\title{
Potencial da produção de aves na Amazônia Legal com enfoque em Rondônia: fomento a proteína animal eficiente de baixo custo
}

A Amazônia Legal no Brasil é dividida em duas partes: a Amazônia Ocidental, composta pelos estados do Amazonas, Acre, Rondônia e Roraima, e a Amazônia Oriental, composta pelos estados do Pará, Maranhão, Amapá, Tocantins e Mato Grosso. O Brasil é o maior exportador de frangos de corte do mundo e praticamente toda a produção de ovos fica no mercado interno. Esse estudo se trata de uma revisão bibliográfica na qual foram consultadas cerca de 54 obras obtidas por meio de bancos de dados eletrônicos. A Amazônia Legal ainda é pouco expressiva na avicultura e essa atividade é uma alternativa para garantir a segurança alimentar e melhoria da qualidade de vida da população local. Na Amazônia Ocidental o Acre e Roraima possuem dois estabelecimentos de beneficiamento de aves e ovos cadastrados com Serviço de Inspeção Estadual enquanto o Amazonas apenas dois estabelecimentos. $O$ estado de Rondônia é o que mais se destaca com cindo estabelecimentos cadastrados. Quanto à Amazônia Oriental, o estado do Maranhão não apresenta nenhum estabelecimento de beneficiamento de aves e ovos cadastrados com Serviço de Inspeção Estadual. Mas, o Pará apresenta três estabelecimentos e o Tocantins apresenta um estabelecimento. Não foram encontrados registros para Amapá e Mato Grosso. Quanto aos estabelecimentos com Serviço de Inspeção Federal na Amazônia Ocidental apenas o estado de Rondônia possui esse tipo de estabelecimentos contando com três unidades. No entanto, na Amazônia Oriental o estado do Pará apresenta três unidades e o estado do Tocantins apresenta uma unidade. Mato Grosso se destaca com cinco abatedouro frigoríficos de aves e é o único que exporta carne de aves. Dessa maneira, ainda são necessários estudos de rentabilidade e maior aplicação das técnicas inovadoras sustentáveis e ampliação do marketing comercial na avicultura na Amazônia Legal para o desenvolvimento sustentável da região.

\section{Poultry production potential in the Legal Amazon with a focus on Rondônia: promotion of low-cost efficient animal protein}

\begin{abstract}
The Legal Amazon in Brazil is divided into two parts: the Western Amazon, made up of the states of Amazonas, Acre, Rondônia and Roraima, and the Eastern Amazon, made up of the states of Pará, Maranhão, Amapá, Tocantins and Mato Grosso. Brazil is the largest exporter of broilers in the world and practically all egg production is in the domestic market. This study is a literature review in which about 54 works obtained through electronic databases were consulted. The Legal Amazon is still not very expressive in poultry farming and this activity is an alternative to guarantee food security and improve the quality of life of the local population. In the Western Amazon, Acre and Roraima have two poultry and egg processing establishments registered with the State Inspection Service, while Amazonas has only two establishments. The state of Rondônia is the one that stands out the most with five registered establishments. As for the Eastern Amazon, the state of Maranhão does not have any poultry and egg processing establishment registered with the State Inspection Service. But Pará has three establishments and Tocantins has one establishment. No records were found for Amapá and Mato Grosso. As for establishments with Federal Inspection Service in the Western Amazon, only the state of Rondônia has this type of establishment with three units. However, in the Eastern Amazon, the state of Pará has three units and the state of Tocantins has one unit. Mato Grosso stands out with five refrigerated poultry slaughterhouses and is the only one that exports poultry meat. In this way, profitability studies and greater application of sustainable innovative techniques and expansion of commercial marketing in poultry farming in the Legal Amazon are still necessary for the sustainable development of the region.

Keywords: Legal Amazon; Poultry farming; Innovation; Commercial marketing; Health Inspection Service; Sustainability.
\end{abstract}

Topic: Desenvolvimento, Sustentabilidade e Meio Ambiente

Reviewed anonymously in the process of blind peer
Received: 02/07/2021

Approved: 28/07/2021
Géssica Raupp Fermiano da Cruz Universidade Federal de Rondônia, Brasil http://lattes.cnpq.br/4824415264562223 http://orcid.org/0000-0001-9406-0423 gessicafermiano@gmail.com

Maria Laís Devolio de Almeida (iD Universidade Federal de Rondônia, Brasil http://lattes.cnpq.br/2575925249186397 http://orcid.org/0000-0001-6707-5670 devolio@gmail.com

Regiane Pandolfo Marmentini (D) Instituto Federal de Rondônia, Brasil http://lattes.cnpq.br/9909815034975027 http://orcid.org/0000-0002-9164-3014 regianepandolfo@gmail.com

\author{
Jerônimo Vieira Dantas Filho (iD) \\ Universidade Federal de Rondônia, Brasil \\ http://lattes.cnpq.br/9897986496945784 \\ http://orcid.org/0000-0002-5965-9438 \\ jeronimovdantas@gmail.com \\ Marlos Oliveira Porto \\ Universidade Federal de Rondônia, Brasil \\ http://lattes.cnpq.br/0604395200725977 \\ http://orcid.org/0000-0002-9398-0065 \\ marlosporto@unir.br \\ Edicarlos Oliveira Queiroz (ii) \\ Universidade Federal de Rondônia, Brasil \\ http://lattes.cnpq.br/5316132077144936 \\ http://orcid.org/0000-0002-5821-7152 \\ edqueiroz@hotmail.com
}

Jucilene Cavali (iD

Universidade Federal de Rondônia, Brasil http://lattes.cnpq.br/3950218993166956 http://orcid.org/0000-0002-2069-4543 jcavali@unir.br
Referencing this:

CRUZ, G. R. F.; ALMEIDA, M. L. D.; MARMENTINI, R. P.; DANTAS FILHO, J. V.; PORTO, M. O.; QUEIROZ, E. O.; CAVALI, J.. Potencial da produção de aves na Amazônia Legal com enfoque em Rondônia: fomento a proteína animal eficiente de baixo custo. Revista Ibero Americana de Ciências Ambientais, v.12, n.7, p.264-278, 2021. DOI: http://doi.org/10.6008/CBPC2179-6858.2021.007.0025 


\section{INTRODUÇÃO}

A Amazônia Continental é composta pelos países Brasil, Bolívia, Peru, Equador, Colômbia, Venezuela, Republica da Guiana, Suriname e Guiana Francesa. O IBGE estima que em 2020 a população brasileira contasse com 211.755 .692 pessoas. A Amazônia Legal no Brasil é dividida em duas partes: a Amazônia Ocidental, composta pelos estados do Amazonas, Acre, Rondônia e Roraima, e a Amazônia Oriental, composta, por exclusão, pelos estados do Pará, Maranhão, Amapá, Tocantins e Mato Grosso. A Amazônia Ocidental contém 7.529.825 pessoas e a Amazônia Oriental contém 21.783.584 pessoas, totalizando 29.313.409 pessoas na Amazônia Legal.

Para que a população da Amazônia Legal tenha segurança alimentar se faz necessária a produção vegetal e animal com orientação e inspeção dos agentes das Secretarias Municipais de Agricultura; das Agências de Defesa Sanitária de cada estado; do Ministério da Agricultura, Pecuária e Abastecimento (MAPA) e também das entidades de pesquisa e de extensão rural. A avicultura é a atividade mais comum dentre os pequenos animais e é uma atividade que garante alimento e fonte de renda para os pequenos produtores, assim como, otimização da área disponível na propriedade. O conhecimento técnico e profissionalismo são fundamentais na avicultura com fins comerciais, pois o elevado giro de recursos financeiros e margens estreitas demandam melhores desempenhos de produtividade (ANATER, 2021).

Em estudo desenvolvido na Reserva de Desenvolvimento Sustentável (RDS) do Uatumã no município de Itapiranga no estado do Amazonas com a criação de galinhas em sistema de semi-confinamento foi demonstrado que os investimentos financeiros gerados pelos projetos possibilitaram uma renda aceitável para o padrão como foi desenvolvido, representando média de ganho de $36 \%$ do valor total investido por projeto (ARAÚJO, 2013; LIMA, 2014). Não só a população da Amazônia Legal necessita ter segurança alimentar, mas a população global que está em expansão. A expansão causa também um aumento na demanda por produtos agropecuários. Os perfis de consumo e as tendências projetadas variam dependendo do nível de desenvolvimento de cada país. Nos países desenvolvidos poderá ocorrer a substituição do consumo da carne vermelha para aves e peixes devido a preocupações ambientais e de saúde (OCDE, 2020).

O Brasil é um dos poucos países que dispõe de terras ocupadas, ainda mal aproveitadas, para a ampliação da produção requerida pelo mundo, preservando os ambientes naturais. O país também possui clima quase sempre favorável, porém tem como dificuldade a legislação tributária que favorece a comercialização de matérias-primas e onera os alimentos processados. Além disso, ainda há enorme deficiência logística que dificulta uma produção eficiente (FERREIRA, 2018). Em 2021 a Organização das Nações Unidas (ONU) reconheceu a importância da agricultura brasileira para a segurança alimentar, o desenvolvimento sustentável e a geração de renda aos agricultores. A agricultura de precisão e a tecnologia baseada em ciência ganharam destaque por elevar a produtividade em 386\% e a área agrícola apenas $83 \%$ no país, sendo que o preço dos alimentos foi reduzido em 50\% e houve a preservação de 120 milhões de hectares de floresta (Belusso et al., 2010; RODRIGUES et al., 2014).

A vantagem de implantar a avicultura é a necessidade de pequena área de terra a ser usada para a 
implantação da granja, podendo estar localizada em terra fraca e desvalorizada. O ciclo de produção é rápido, dando um bom retorno num período relativamente curto (CRUZ et al., 2016). A avicultura industrial no Brasil, responsável por $98 \%$ da oferta de frango, vem passando por uma extraordinária revolução tecnológica, de modo que os ganhos de produtividade vêm batendo sucessivos recordes ano após ano. A redução excepcional no tempo de abate (de 112 dias para 41 dias), o aumento no peso por animal abatido (de 1,5 kg para $2,8 \mathrm{~kg}$ ), o melhoramento genético das matrizes, alimentação e nutrição dos animais, melhorias sanitárias e combate a doenças, a melhoria no manejo e outras variáveis, favoreceram enormemente a atividade e a colocaram entre as melhores do mundo (FERREIRA et al., 2010).Em 2019, o Brasil contava com 1.466.556.199 cabeças de galináceos (galos, galinhas, frangos, frangas, pintos e pintainhas), sendo que a região Norte contava com 49.326 .851 de cabeças (3,36\%), a região Nordeste contava com 183.323 .064 de cabeças (12,50\%), a região Sudeste 372.128 .935 de cabeças (25,37\%), Sul 674.491 .017 de cabeças $(45,99 \%)$, Centro-Oeste 187.286.332 de cabeças (12,77\%). No entanto, em relação às codornas o Brasil contava com 17.418.818 de cabeças, sendo que a região Norte contava com 174.146 de cabeças ( $1,00 \%)$, a região Nordeste contava com 2.520 .787 de cabeças (14,47\%), a região Sudeste 11.055 .725 de cabeças $(63,47 \%)$, Sul 2.847 .047 de cabeças (16,34\%), Centro-Oeste 821.113 de cabeças (4,71\%) (SILVA et al., 2020).

A carne de frango é a proteína mais consumida no Brasil, sendo uma carne de excelente conteúdo nutricional e com preços acessíveis e relativamente estáveis, quando comparada a outras proteínas, derivadas de outras espécies (FERREIRA et al., 2010). O Brasil é o 3o maior produtor de frangos de corte do mundo, atrás apenas dos Estados Unidos e da China. Em relação à exportação o Brasil fica em 1‥ Quanto ao consumo o Brasil fica em 4 ㅇ lugar atrás apenas dos Estados Unidos, China e União Europeia (EMBRAPA, 2021). A produção brasileira de carne de frango aumentou de 13.245 mil toneladas em 2019 para 13.845 mil toneladas em 2020. Em 2020 69\% da carne de frango produzida no Brasil ficou no mercado interno e 31\% foi destinada à exportação. $\mathrm{O}$ consumo per capita de carne de frango no país aumentou de $42,84 \mathrm{~kg} / \mathrm{hab}$. em 2019 para 45,27 kg/hab. em 2020. Em 2020 os produtos exportados de carne de frango foram 66,99\% corte, $25,26 \%$ inteiros, $3,14 \%$ salgados, $2,45 \%$ embutidos, $2,16 \%$ industrializados (ABPA, 2021).

No acumulado do ano de 2020, foram abatidas 6 bilhões de cabeças de frango no Brasil, aumento de 3,3\% (+190,83 milhões de cabeças) em relação ao ano de 2019. O peso acumulado das carcaças no abate de frangos em 2020 alcançou 13,77 milhões de toneladas, representando aumento de 1,8\% (+249,08 mil toneladas) em relação ao ano de 2019. A Região Sul respondeu por $60,7 \%$ do abate nacional de frangos em 2020, seguida pelas Regiões Sudeste (19,3\%), Centro-Oeste (14,1\%), Nordeste $(4,2 \%)$ e Norte $(1,7 \%)$. Apesar do aumento, os estados do Mato Grosso (-11,14 milhões de cabeças) e Pará (-5,63 milhões de cabeças) apresentaram redução na produção. Esses dois estados que pertencem a Amazônia Legal estão no ranking dos 10 que mais produzem no país, sendo que Mato Grosso está em 70 e Pará em 10․ Roraima e Amapá foram as únicas Unidades da Federação que não apresentaram qualquer abate de frangos sob algum tipo de inspeção sanitária. Apesar do aumento da produção houve redução no volume de exportação em relação ao ano anterior em 1,3\% e queda nos preços internacionais (-13,3\%) (SILVA et al., 2020). Em comparação com a carne bovina e suína, a carne de frango é a de menor valorização internacional embora tenha aumentado 
7,5\% em 2021 (ARSHAD et al., 2019).

Atualmente a China é o maior importador da carne de frango do Brasil. Porém, Arábia Saudita, Japão, Emirados Árabes Unidos, África do Sul, Hong-Kong e Coréia do Sul também são importantes parceiros comerciais. A China passou a ser um dos maiores compradores de proteína animal do Brasil a partir do momento em que foi diagnosticada a peste suína africana no rebanho dos suínos na China no final do segundo semestre de 2018 (SILVA et al., 2020).

Ao que concerne a valores de mercado, o preço médio do frango resfriado com ICMS posto no frigorífico (R\$/kg), em 2020, foi de $R \$ 5,10 / \mathrm{kg}$ e no ano anterior foi de $\mathrm{R} \$ 4,70 / \mathrm{kg}$. No comparativo 2020/2019, verificou-se aumento de $8,55 \%$ do preço médio recebido pelo produtor. 0 ritmo de crescimento dos preços do frango se intensificou no segundo semestre, porém com menos força que o das demais carnes concorrentes favorecendo à alta de demanda interna pela carne de frango, o que colaborou para o recorde de produção de abate de frangos apontados pelo IBGE no $4^{\circ}$ trimestre de 2020. Os Índices IPCA/IBGE (Índice de Preços ao Consumidor Amplo) apresentaram variação acumulada no ano positiva tanto para o subitem frango inteiro $(+17,16 \%)$, como para o subitem frango em pedaços $(+14,08 \%)$. Também no campo positivo, mas num patamar inferior, o Índice geral da inflação de 2020 foi de 4,52\% (ARSHAD et al., 2019).

A produção brasileira de ovos passou de 49.055.709.215 unidades em 2019 para 53.533.542.389 unidades em 2020. Em 2020 99,7\% dos ovos produzidos no Brasil ficou no mercado interno e 0,3\% foi destinado à exportação. $O$ consumo per capita de ovos no país aumentou de 230 unid./hab. em 2019 para 251 unid./hab. em 2020. Em 2020 64,45\% dos ovos foram exportados in natura enquanto 35,55\% foram exportados industrializados (ABPA, 2021).

A produção de ovos de galinha foi de 3,96 bilhões de dúzias em 2020, apresentando um aumento de 3,0\% em relação ao ano anterior. Produziu-se 115,05 milhões de dúzias de ovos a mais, em nível nacional, no comparativo 2020/2019. Os ovos apresentam alto valor nutricional e uma proteína de valor mais acessível em comparação às carnes (SILVA et al., 2020). Dos estados pertencentes à Amazônia Legal que estiveram em destaque no ranking nacional foram Mato Grosso em 6ㅇ e Amazonas em 13‥ Mato Grosso apresentou aumento de $(+12,46$ milhões de dúzias) em relação ao ano anterior. O IPCA/IBGE para ovo de galinha acumulado em 2020 foi de $11,42 \%$. 80,7\% dos ovos foram para consumo enquanto 19,3\% foram para incubação. Além do mais, o Amapá foi a única Unidade da Federação que não apresenta granja sob inspeção sanitária (SILVA et al., 2020).

Em maio de 2021 os excedentes de mercadoria têm imposto aos produtores de ovos retrocesso de preço, apesar disso na comparação com o mesmo período do ano passado ainda apresenta índice positivo de $3 \%$. Enquanto isso o milho e o farelo de soja seguem valorizados, no caso do milho principalmente pela elevada procura doméstica e preocupações quanto à segunda safra e no caso da soja a demanda segue firme tanto interna quanto externa. Esse cenário tem reduzido a rentabilidade para o avicultor principalmente nas regiões que a produção de milho e soja são baixos.

O objetivo do estudo foi levantar dados sobre a avicultura na Amazônia Legal com foco nas granjas e nos estabelecimentos de beneficiamento de aves e ovos cadastrados com Serviço de Inspeção Estadual e 
também no Serviço de Inspeção Federal, assim como os sistemas de cultivo, técnicas inovadoras sustentáveis e marketing comercial na Amazônia Legal com enfoque no estado de Rondônia.

\section{METODOLOGIA}

Trata-se de um estudo de levantamento de dados, realizado por meio de consulta a base de dados de periódicos da CAPES, repositórios institucionais e relatórios técnicos. O levantamento das informações caracteriza-se como sendo do tipo descritivo exploratório, de caráter qualitativo, visando a análise, a comparação e o cruzamento de dados entre diversos artigos e literaturas relacionadas ao tema central do estudo (PEREIRA et al., 2018).

A pesquisas e coletas de dados foram realizadas em maio de 2021, a partir de questões levantadas sobre o tema foram consultadas cerca de 54 obras por meio de revisões bibliográficas, tendo sido empregados artigos científicos, livros e referências em bancos de dados eletrônicos e nas bases bibliográficas: Google, Google Acadêmico, Amazon, Scielo, IBGE. Para coleta das informações, foram buscados os seguintes descritores: Amazônia, Avicultura, Marketing comercial, Serviço de Inspeção Sanitária, Sustentabilidade.

\section{RESULTADOS E DISCUSSÃO}

A População estimada em 2020 e Identificação e site das Agências de Defesa Sanitárias dos estados da Amazônia Legal (Tabela 1). A Amazônia Legal contém 13,84\% da população brasileira, sendo o Pará o estado com maior número de pessoas, seguido por Maranhão, Amazonas, Mato Grosso, Rondônia, Tocantins, Acre, Amapá e Roraima.

Tabela 1: População estimada em 2020 e Identificação e site das Agências de Defesa Sanitárias dos Estados da Amazônia Legal.

\begin{tabular}{|c|c|c|c|}
\hline Parte/Estado & $\begin{array}{l}\text { População estimada } \\
\text { em } 2020\end{array}$ & Identificação & Site \\
\hline $\begin{array}{l}\text { Amazônia } \\
\text { Ocidental }\end{array}$ & 7.529 .825 & & \\
\hline Amazonas & 4.207.714 pessoas & $\begin{array}{l}\text { Agência de Defesa Agropecuária e Florestal do } \\
\text { Amazonas (ADAF) }\end{array}$ & http://www.adaf.am.gov.br/ \\
\hline Acre & 894.470 pessoas & $\begin{array}{l}\text { Instituto de Defesa Agropecuária e Florestal do } \\
\text { Acre (IDAF) }\end{array}$ & http://idaf.acre.gov.br/ \\
\hline Rondônia & 1.796 .460 pessoas & $\begin{array}{l}\text { Agência de Defesa Sanitária Agrosilvopastoril do } \\
\text { Estado de Rondônia (IDARON) }\end{array}$ & http://www.idaron.ro.gov.br/ \\
\hline Roraima & 631.181 pessoas & $\begin{array}{l}\text { Agência de Defesa Agropecuária de Roraima } \\
\text { (ADERR) }\end{array}$ & http://www.aderr.rr.gov.br/ \\
\hline $\begin{array}{l}\text { Amazônia } \\
\text { Oriental }\end{array}$ & 21.783.584 & & \\
\hline Pará & 8.690 .745 pessoas & $\begin{array}{l}\text { Agência de Defesa Agropecuária do Estado do } \\
\text { Pará (ADEPARÁ) }\end{array}$ & http://www.adepara.pa.gov.br/ \\
\hline Maranhão & 7.114.598 pessoas & $\begin{array}{l}\text { Agência Estadual de Defesa Agropecuária do } \\
\text { Maranhão (AGED) }\end{array}$ & http://www.aged.ma.gov.br/ \\
\hline Amapá & 861.773 pessoas & $\begin{array}{l}\text { Agência de Defesa e Inspeção Agropecuária do } \\
\text { Estado do Amapá (DIAGRO) }\end{array}$ & http://www.diagro.ap.gov.br/ \\
\hline Tocantins & 1.590 .248 pessoas & $\begin{array}{l}\text { Agência de Defesa Agropecuária do Tocantins } \\
\text { (ADAPEC) }\end{array}$ & http://adapec.to.gov.br/ \\
\hline Mato Grosso & 3.526 .220 pessoas & $\begin{array}{l}\text { Instituto de Defesa Agropecuária de Mato } \\
\text { Grosso (INDEA) }\end{array}$ & http://www.indea.mt.gov.br/ \\
\hline
\end{tabular}

Fonte: Adaptado de Silva et al. (2020).

Em 2020 o consumo per capita de carne de frango foi de 45,27 kg/hab. e o consumo per capita de 
ovos foi de 251 unid./hab. (ABPA, 2021). Portanto, levando em consideração a população estimada para a Amazônia Ocidental nesse mesmo ano, existiu a demanda de $340.875 .177,8 \mathrm{~kg}$ de carne de frango e 1.889.986.075 unidades de ovos enquanto na Amazônia Oriental existiu a demanda de 986.142.847,7 kg de carne de frango e 5.467.679.584 unidades de ovos.

A Tabela 2 apresenta o número de cabeças de galináceos e codornas em cada estado da Amazônia Legal. Segundo dados do IBGE a Amazônia Ocidental possuía 10.866.822 cabeças de galináceos em 2019 e a Amazônia Oriental possuía 104.689.205 cabeças de galináceos. A Amazônia Ocidental possuía 146.173 cabeças de codornas e a Amazônia Oriental possuía 212.073 cabeças de codornas. Portanto, há um maior número de animais na Amazônia Oriental do que na Amazônia Ocidental.

Tabela 2: Números de cabeças de galináceos e codornas em cada estado da Amazônia Legal.

\begin{tabular}{lll}
\hline Parte/Estado & Galináceos (cabeças) & Codornas (cabeças) \\
\hline Amazônia Ocidental & $\mathbf{1 0 . 8 6 6 . 8 2 2}$ & $\mathbf{1 4 6 . 1 7 3}$ \\
\hline Amazonas & 4.211 .718 & 38.484 \\
Acre & 2.788 .208 & 7.289 \\
Rondônia & 3.156 .296 & 87.000 \\
Roraima & 710.600 & 13.400 \\
\hline Amazônia Oriental & $\mathbf{1 0 4 . 6 8 9 . 2 0 5}$ & $\mathbf{2 1 2 . 0 7 3}$ \\
\hline Pará & 30.393 .850 & 26.905 \\
Maranhão & 11.850 .372 & 6.869 \\
Amapá & 83.468 & - \\
Tocantins & 7.982 .711 & 1.068 \\
Mato Grosso & 54.378 .804 & 177.231 \\
\hline
\end{tabular}

A Tabela 3 apresenta o número de granjas cadastradas na Agência de Defesa Sanitária de cada estado da Amazônia Legal. Destacam-se os estados do Pará, Rondônia, Tocantins, Acre, Maranhão, e Amazonas no número de granjas cadastradas.

Tabela 3: Números de granjas cadastradas na Agência de Defesa Sanitária de cada estado da Amazônia Legal.

\begin{tabular}{|c|c|c|c|}
\hline Parte/Estado & № de granjas & Segmento & \\
\hline Amazônia Ocidental & 210 & & \\
\hline Amazonas & 35 & Postura & \\
\hline Acre & $48 / 10$ & Corte/postura & \\
\hline Rondônia & 107 & $\begin{array}{l}\text { Corte/postura/Aves } \\
\text { de quintal/Incubatório/Matrizeiro/Ornamentais }\end{array}$ & caipiras/fundo \\
\hline Roraima & 10 & Não especificado & \\
\hline Amazônia Oriental & 387 & & \\
\hline Pará & $218 / 27$ & Corte/postura & \\
\hline Maranhão & $40 / 02$ & Corte/postura & \\
\hline Amapá & Não encontrado & Não encontrado & \\
\hline Tocantins & 100 & Não especificado & \\
\hline Mato Grosso & Não encontrado & Não encontrado & \\
\hline
\end{tabular}

Fonte: ADAF (2021); ADAPEC (2020); ADEPARÁ (2020); AGED (2020); IDARON (2020); RORAIMA (2021).

Dos estados da Amazônia Ocidental o estado de Rondônia apresenta destaque pelo número de estabelecimentos cadastradas no Serviço de Inspeção Estadual (SIE), com 107 granjas cadastradas em 2020 e 5 estabelecimentos de beneficiamento de aves e ovos (Tabela 3 e Tabela 5). 0 estado é ainda o único da Amazônia Ocidental que possui abatedouro frigorífico cadastrado no Serviço de Inspeção Federal (SIF) (Tabela 6), contando com 3 unidades de Razão Social Kaefer Agroindustrial LTDA e Nome Fantasia Globoaves localizadas na cidade de Espigão do Oeste. A empresa comercializa seus produtos com a marca Avenorte.

A Globoaves de Espigão do Oeste é o único frigorífico de aves instalado em Rondônia habilitado para 
exportação e está negociando com parceiros para enviar seus produtos ao exterior. Em 2020 o frigorífico aumentou o abate de 300 mil aves por semana para 360 mil aves por semana com projeção de aumento para 480 mil aves por semana em 2021. A empresa também distribui na região de Rondônia cerca de 75 mil pintainhos semanalmente entre pintos de corte, postura e colonial que são direcionados para lojas agropecuárias e pequenos produtores rurais e projeta aumentar esse número para 110 mil pintainhos (Belusso et al, 2010; RODRIGUES et al., 2014).

Observa-se que apesar de Rondônia estar em 4ํ no ranking populacional da Amazônia Legal o estado está com mais granjas cadastradas no estado (107) do que Maranhão (42), Amazonas (35) e na divulgação das informações em relação ao Mato Grosso cujos dados não foram encontrados no site da Agência de Defesa Sanitária do Estado.

As 107 granjas cadastradas na Agência de Defesa Sanitária do Estado de Rondônia estão integradas à empresa Globoaves; ou seja; recebem o pintinho, a ração, os medicamentos e a orientação técnica dos médicos veterinários e zootecnistas e em contrapartida fornecem a estrutura e a mão de obra para a empresa integradora. Ao final do ciclo de produção, que é em média de 45 dias, o integrado vende o frango para a empresa e recebe por peso e conversão alimentar. Desses integrados 41 adotam o sistema de cultivo por pressão positiva e 66 por pressão negativa - dark house, com capacidade de alojamento para 30 a 37 mil aves. As granjas integradas que se destacam no estado pela sua produção de ovos são: Granja Serra dourada - Cacoal, Granja Rabelo - Rolim de Moura, Granja Piarara - Cacoal e Espigão D’Oeste, Granja Brasil - Vilhena, Granja Aviron - Porto Velho, Granja Vilhena - Vilhena. As granjas podem conter mais de um aviário.

A Tabela 4 apresenta o número de granjas avícolas cadastradas na Agência de Defesa Sanitária de Rondônia nos anos de 2020 e 2021. Observa-se que houve um aumento de 42 granjas avícolas antes de encerrar o primeiro semestre de 2021 demonstrando o aquecimento do setor.

Tabela 4: Números de granjas avícolas cadastradas na Agência de Defesa Sanitária de Rondônia nos anos de 2020 e 2021.

\begin{tabular}{lll}
\hline Categoria & № em 2020 & No em 2021 \\
\hline Com menos de 1 mil aves & 21 & 50 \\
Cadastrado/Registrado no Serviço Veterinário Estadual (SVE) & 84 & 97 \\
Certificado no MAPA & 2 & 2 \\
\hline Classificação & & \\
\hline Corte & 57 & 69 \\
Postura & 40 & 55 \\
Aves caipiras/fundo de quintal & 6 & 18 \\
Incubatório & 2 & 3 \\
Matrizeiro & 1 & 1 \\
Ornamentais & 1 & 2 \\
Subsistência & - & 1 \\
\hline TOTAL & 107 & 149
\end{tabular}

Fonte: Adaptado de IDARON (2020a; 2021).

A produção de aves no estado de Rondônia tem demonstrado um crescente aumento nos últimos anos, onde os números de produção/consumo de ovos e carne de frango têm estimulado o fortalecimento do setor no estado (BOROVIEC et al., 2020). O aumento do valor da carne bovina aqueceu o consumo de produtos avícolas em Rondônia. $O$ aumento do valor da carne bovina ocorreu principalmente a partir de 2020 com a pandemia da doença Covid-19, abertura de novos mercados e alta do dólar. A pandemia foi declarada 
no Brasil no dia 11 de março de 2020 pela Organização Mundial da Saúde (OMS). Tem como agente causador o Coronavírus (SARS-CoV-2) que surgiu na cidade de Wuhan na China e se disseminou pelo mundo. Além disso, nesse mesmo ano também houve a abertura de novos mercados para a exportação da carne bovina e ampliação das vendas em outros locais. Entre os países importadores de carne bovina brasileira estão China, Egito, Indonésia, Kuwait, Marrocos, Emirados Árabes Unidos, Tailândia.

Em momentos de crise demanda pelo dólar aumenta, pois, por ser uma das moedas mais fortes e sólidas do mundo as pessoas compram a moeda para se defender da crise. O real acaba sendo desvalorizado porque o modelo de câmbio do Brasil é o flutuante (LAFRATTA, 2020). Em 2020 a cotação do dólar ultrapassou a casa dos $\mathrm{R} \$ 5,00$. O Brasil sofre uma grande interferência da alta do dólar, porque exporta mais commodities, enquanto importa produtos acabados. Esse desequilíbrio é bom para os exportadores, porém reduz o poder de compra da população brasileira (BECK, 2015).

Além do mais, a Câmara Setorial de Aves e Suínos em Rondônia que está vinculada ao Conselho Estadual de Desenvolvimento Rural Sustentável (CEDRS/RO) dentro da estrutura organizacional da Secretaria de Estado de Agricultura (SEAGRI) tem discutido os desafios e proposto apoio na área tributária, na compra de equipamentos, na estruturação da avicultura com novas tecnologias, na disponibilização de linhas de créditos juntos aos bancos oficiais com o intuito de fortalecimento ao setor. E também a Entidade Autárquica de Assistência Técnica e Extensão Rural do Estado de Rondônia (EMATER), em parceria com a Companhia Nacional de Abastecimento (Conab) tem trabalhado em alternativas para que o pequeno produtor consiga concorrer com os grandes produtores. São ações que abrangem o Programa de Aquisição de Alimentos (PAA) e o Programa de Vendas em Balcão (ProVB) (EMATER, 2021).

Apesar do aumento do consumo dos produtos avícolas também houve incremento significativo nos custos de produção do setor devido ao aumento do valor dos insumos (SILVA et al., 2020). A Tabela 5 apresenta o número de estabelecimentos de beneficiamento de aves e ovos da Amazônia Legal cadastrados com Serviço de Inspeção Estadual. O estado de Rondônia possui 5 estabelecimentos cadastrados, seguido pelos estados do Pará (3), Amazonas (2), Acre (1), Roraima (1), Tocantins (1). Vale destacar que em Rondônia as granjas que fornecem a matéria-prima para as agroindústrias são dos proprietários das agroindústrias e por esse motivo não há um cadastro de granja e sim apenas de agroindústria em Rondônia (SOUZA, 2019).

Tabela 5: Estabelecimentos de beneficiamento de aves e ovos da Amazônia Legal cadastrados com Serviço de Inspeção Estadual.

\begin{tabular}{llll}
\hline Parte/Estado & $\begin{array}{l}\text { No } \\
\text { Estadual }\end{array}$ & Identificação & Fonte \\
\hline $\begin{array}{l}\text { Amazônia } \\
\text { Ocidental }\end{array}$ & 9 & & \\
\hline Amazonas & 1 & Abatedouro de aves & (ADAF, 2021) \\
Acre & 1 & Enidade de beneficiamento de ovos e derivados & (OFICIO/IDAF/PESA \\
Rondônia & 1 & Agroindústria, Abatedouro frigorifico de aves domésticas & (IDARON, 2020b) \\
& 2 & $\begin{array}{l}\text { Indústria de ovos de aves domésticas } \\
\text { Indústria, Unidade de beneficiamento de ovos e derivados de } \\
\text { aves domésticas } \\
\text { Agroindústria, Unidade de beneficiamento de ovos e } \\
\text { derivados de codorna }\end{array}$
\end{tabular}




\begin{tabular}{llll} 
Roraima & 1 & Empresa de ovos caipira & (RORAIMA, 2020) \\
\hline Amazônia Oriental & 4 & & \\
\hline Pará & 2 & Matadouro de Aves e Coelhos & (ADEPARA, 2020b) \\
Maranhão & 1 & Granja Avícola & (AGED, 2020b) \\
Amapá & - & Não há & (NORTE AGROPECUÁRIO, \\
Tocantins & - & Não encontrado & 2020) \\
Mato Grosso & 1 & Abatedouro de aves &
\end{tabular}

Fonte: ADAF (2021); ADEPARA (2020b); AGED (2020b); IDARON (2020b).

Cabe enfatizar que não há padronização nem dos sites das Agências de Defesa Sanitárias para a localização das listas dos estabelecimentos com Serviço de Inspeção Estadual e nem das nomenclaturas para a identificação dos estabelecimentos e isso causa dificuldade em realizar a pesquisa.

A Tabela 6 apresenta os estabelecimentos de beneficiamento de aves e ovos da Amazônia Legal cadastrados com Serviço de Inspeção Federal. O estado do Mato Grosso se destaca com 5 abatedouros frigoríficos de aves e é o único que exporta carne de aves para a China. Os estabelecimentos que exportam são a UNIÃO AVÍCOLA AGROINDUSTRIAL LTDA e a BRF S. A. (MAPA, 2021). Além do estado do Mato Grosso, Rondônia (3), Pará (3) e Tocantins (1) também possuem abatedouros frigoríficos de aves cadastrados com Serviço de Inspeção Federal. Em relação à quantidade de abate em 2020 observa-se que o estado do Tocantins, apesar de possuir apenas um abatedouro frigorífico de aves apresentou um valor de 20.534 .964 acima do estado de Rondônia 16.252.008 que possui três abatedouros frigoríficos de aves.

Tabela 6: Estabelecimentos de beneficiamento de aves e ovos da Amazônia Legal cadastrados com Serviço de Inspeção Federal.

\begin{tabular}{|c|c|c|c|}
\hline Parte/Estado & $\begin{array}{l}\text { № } \\
\text { Federal }\end{array}$ & Identificação & $\begin{array}{l}\text { Quantidade de abate sob a responsabilidade dos SIPAs/DFAs* } \\
\text { em } 2020\end{array}$ \\
\hline $\begin{array}{l}\text { Amazônia } \\
\text { Ocidental }\end{array}$ & 3 & & \\
\hline Amazonas & - & - & - \\
\hline Acre & - & - & - \\
\hline Rondônia & 3 & $\begin{array}{l}\text { ABATEDOURO FRIGORÍFICO } \\
\text { AVES }\end{array}$ & 16.252 .008 \\
\hline
\end{tabular}

\begin{tabular}{|c|c|c|c|c|}
\hline Roraima & - & - & & - \\
\hline Amazônia Oriental & 9 & & & - \\
\hline Pará & 3 & $\begin{array}{l}\text { ABATEDOURO } \\
\text { AVES }\end{array}$ & FRIGORÍFICO & 48.206 .158 \\
\hline Maranhão & - & - & & - \\
\hline Amapá & - & - & & - \\
\hline Tocantins & 1 & $\begin{array}{l}\text { ABATEDOURO } \\
\text { AVES }\end{array}$ & FRIGORÍFICO & 20.534 .964 \\
\hline Mato Grosso & 5 & $\begin{array}{l}\text { ABATEDOURO } \\
\text { AVES }\end{array}$ & FRIGORÍFICO & 216.102 .668 \\
\hline TOTAL & 12 & & & \\
\hline
\end{tabular}

*Serviço de Inspeção de Produtos de Origem Animal (SIPAs) e das Delegacias Federais de Agricultura (DFAs). Fonte: MAPA (2020a).

Os estabelecimentos que realizam o abate das aves e beneficiam as matérias-primas provenientes desses animais são necessários para garantir a segurança dos alimentos e garantir que esses alimentos não causarão doenças nos consumidores. Nesses estabelecimentos deve-se observar o Decreto $n^{\circ}$ 9.013/2017 e a Portaria MAPA n 368/1997, além das normas complementares e orientações técnicas específicas de cada 
área como, por exemplo, a Portaria n² 210, de 10 de novembro de 1998 que é o Regulamento Técnico da Inspeção Tecnológica e Higiênico-Sanitária de Carnes de Aves e a Portaria no 1, de 21 de fevereiro de 1990 que aprova as Normas Gerais de Inspeção de Ovos e Derivados (MAPA, 2020b). Além das legislações municipais e estaduais relacionadas às agroindústrias.

\section{Sistemas de cultivo}

Atualmente os avicultores tem se ajustado para implantar sistemas de criação que melhorem o desempenho e o bem-estar das aves com o objetivo de otimizar a produção considerando o comportamento natural das aves, o microclima necessário a mantê-las dentro da zona de termoneutralidade e inclusões de alimentos alternativos como tentativa de diminuir os custos de produção (SANTOS et al., 2020). Os sistemas de produção na avicultura podem ser extensivos, semi-intensivos e intensivos (PAULINO et al., 2019). No sistema intensivo os animais ficam completamente confinados dentro do aviário enquanto no sistema semiintensivos os animais ficam uma parte da vida confinados e depois são soltos, podendo entrar e sair do aviário. No entanto, no sistema extensivo os animais ficam totalmente soltos e desconsidera-se os índices zootécnicos e divisão por fases de produção.

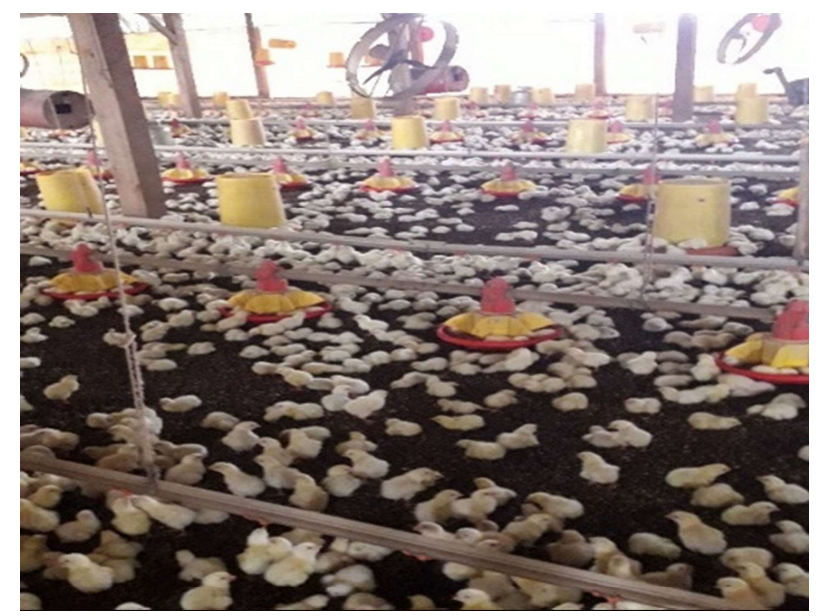

Figura 1: Interior do aviário com sistema de pressão positiva (intensivo) na Granja Jucelino em Cacoal-RO.

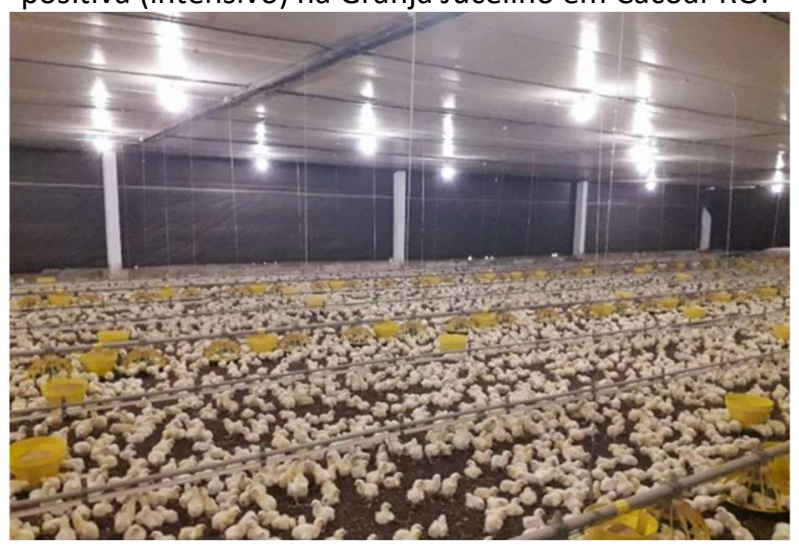

Figura 3: Interior do aviário com sistema pressão negativa ou dark house (intensivo) na Granja Dalva em Cacoal-RO.

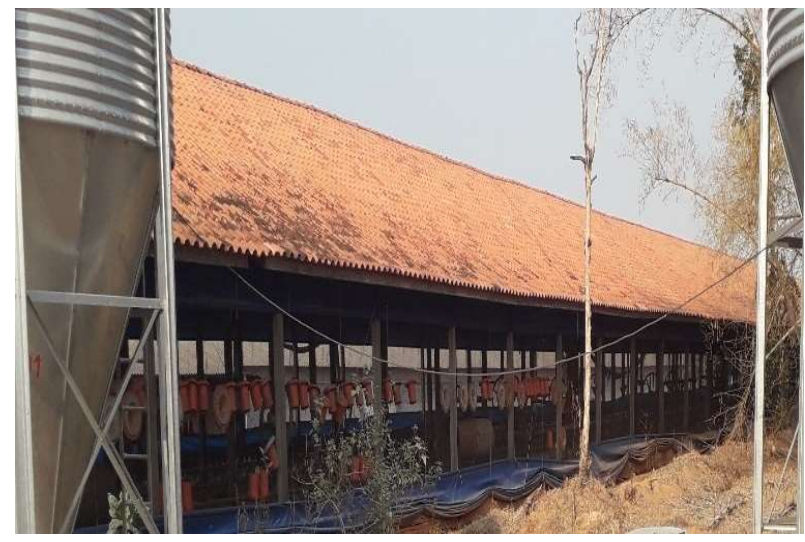

Figura 2: Exterior do aviário com sistema de pressão positiva (intensivo) na Granja Jucelino em Cacoal-RO.

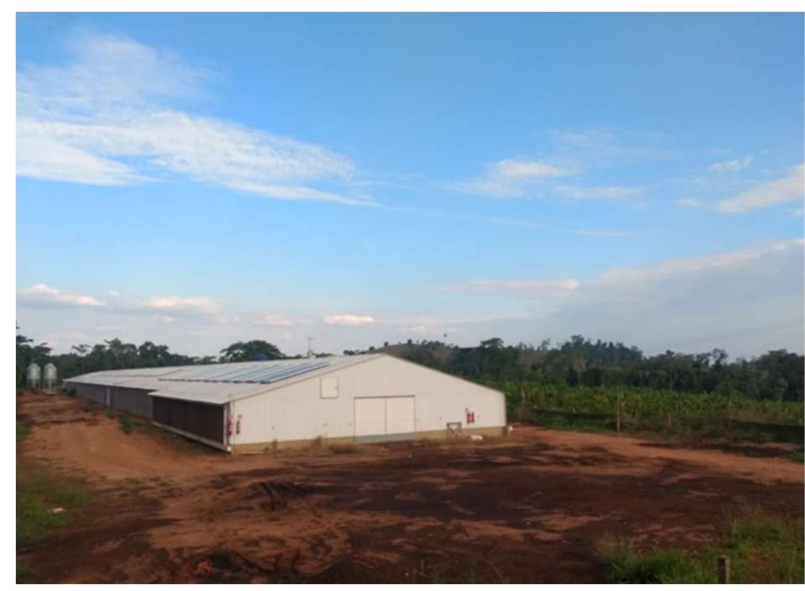

Figura 4: Exterior do aviário com sistema pressão negativa ou dark house (intensivo) na Granja Dalva em Cacoal-RO.

O sistema intensivo pode ser por pressão positiva ou por pressão negativa. No sistema de pressão 
positiva o aviário é aberto (Figuras 1 e 2) e no sistema de pressão negativa ou dark house o aviário é todo fechado com uma extremidade contendo uma placa evaporativa de água e outra extremidade contendo exaustores que puxam essa água com o objetivo de resfriar o aviário (Figuras 3 e 4) (FERREIRA et al., 2010; PAULINO et al., 2019).

\section{Técnicas inovadoras sustentáveis}

A sustentabilidade envolve o desenvolvimento econômico, a responsabilidade social e a gestão ambiental. A prosperidade econômica do Brasil no longo prazo dependerá da solidez da agricultura, da agroindústria e da capacidade acadêmica e inovadora. Em um mundo globalizado a concorrência se torna cada vez mais acirrada e por esse motivo os investimentos em mão-de-obra especializada e em pesquisa se fazem necessários (FERREIRA et al., 2010).

No Brasil $12 \%$ dos produtores são responsáveis por aproximadamente $85 \%$ da produção, ou seja, a maioria dos produtores rurais ainda não tem acesso às inovações e isso se faz necessário para reduzir a pobreza no campo. Preparar pessoas e incentivar a construção de mecanismos que permitam a superação das imperfeições de mercado é fundamental. Geralmente, o pequeno produtor compra os insumos e equipamentos com preços elevados e tem escala de produção baixa o que reduz a rentabilidade (FERREIRA et al., 2010). A indústria também desempenha papel estratégico na economia. $O$ beneficiamento das matérias-primas pelas indústrias agrega valor aos produtos brasileiros e melhora a economia do país. Os seus ganhos se propagam através das conexões de produção, investimento, tecnologia e geração de renda (FERREIRA et al., 2010).

O frango pode ser beneficiado com a elaboração de produtos enlatados, empanados, embutidos fermentados, defumados, reestruturados. E, também podem ser aproveitados os miúdos (PIMENTEL et al., 2019). No entanto, os ovos são utilizados nas formulações de vários alimentos por terem características de coagulabilidade por ação do calor, capacidade formadora de espuma e ação emulsificante, além da cor e do aroma que conferem. A clara e a gema podem ser vendidas separadamente como produtos líquidos pasteurizados, congelados ou desidratados (ovo em pó). Esse processamento gera economia em transporte, menores perdas com quebras, melhor conservação do produto aumentando o prazo comercial, fornecimento de um produto de qualidade tecnológica e sanitária e praticidade na utilização (CUNHA et al., 2012). Outros produtos derivados são albumina; globulina; lisozima; ovalbumina; conalbumina; ovomucoide; lecitina de ovo.

Atualmente tem aumentado a demanda para o frango e o ovo caipira devido à busca por uma alimentação mais natural. A Norma ABNT NBR 16389:2015 traz a terminologia de Sistema de produção de frango caipira/colonial/capoeira como sendo o Sistema de criação de aves comerciais destinadas à produção de carne, através de raças e linhagens de crescimento lento, com acesso às áreas livres para pastejo em sistema semiextensivo e que não recebam, via ração, melhoradores de desempenho e anticoccidianos profilaticamente (ABNT, 2015). A Embrapa desenvolveu o Sistema para a Produção de Galinhas Caipiras (Procap) que é um sistema sustentável e alternativo para a produção de galinhas caipiras naturalizadas e foi 
desenvolvido a partir da realidade apresentada pelo pequeno produtor e agricultor familiar, que possui, via de regra, limitada capacidade de investimento (QUINZEIRO NETO et al., 2017).

A alimentação dos animais deve ser equilibrada nutricionalmente, sendo econômica e palatável. Além disso, deve ter elevado valor nutritivo, baixo teor de fibra e alta digestibilidade. Sendo assim, para a alimentação dos animais é preciso conhecer o potencial nutritivo em cada situação (grãos, folhas, frutos, etc.) e processá-lo sem perdas, torná-lo disponível sempre que necessário e ofertá-lo às aves de acordo com as necessidades e peculiaridades de cada fase de criação. Pode-se utilizar o milho (grão), sorgo (grão), mandioca (folhas secas e moídas, as raspas e as cascas das raízes), feijão guandu (folhas secas e moídas e sementes), leucena (folhas secas e moídas). Assim como a gramínea existente nos piquetes, leguminosas, frutas e hortaliças, insetos, minhocas, dentre outras. As folhas tenras são mais ricas e nutritivas que folhas maduras, com maior teor de fibra. Além disso, faz-se necessário o fornecimento de uma fonte mineral, como o sal comum, fosfato bicálcico e calcário calcítico. Quando a alimentação das aves é à base de mandioca, a pigmentação da carne e ovos pode ser melhorada com a utilização de plantas pigmentantes na ração, por exemplo, as sementes de urucum (Bixa orellana L.) (QUINZEIRO NETO et al., 2017; EMBRAPA, 2018).

Como exemplos de técnicas inovadoras sustentáveis na avicultura há a elaboração de biofertilizantes e de "biogás" a partir de cama de frango e a elaboração de diesel verde a partir de carcaças de aves. O uso da energia solar também tem se destacado nos aviários. O tratamento de efluentes nos abatedouros de frangos também tem sido fundamental na gestão ambiental (VILVERT et al., 2020).

O uso de biofertilizantes tem se intensificado para a realização de adubação em hortas e/ou pastagens. A cama de frango (dejetos das aves tanto de corte quanto de postura que reveste o chão do aviário) é um recurso comumente utilizado para tal finalidade e é comercializada pelos avicultores quando há o procedimento da troca de cama do aviário (PIMENTEL et al., 2019). Os biofertilizantes possuem em sua composição microrganismos capazes de realizar a fermentação da cama a fim de tornar o local aplicado rico em nutrientes (JUNQUEIRA, 2015). Além de utilizado na adubação, a cama de frango também serve de alternativa para geração de energia, chamado de "biogás", composto de 70\% de metano (LANSING et al., 2008; SANTOS et al., 2016).

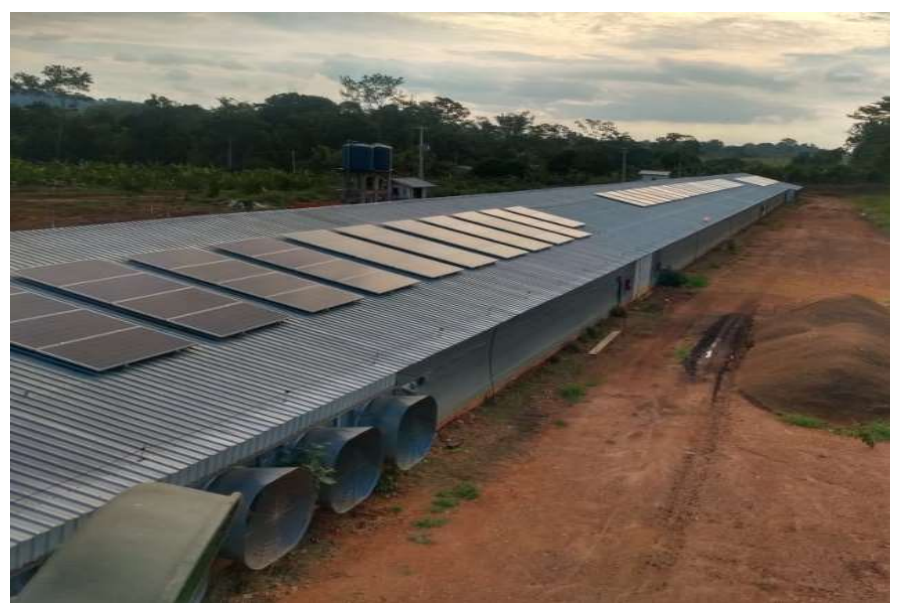

Figura 5: Sistema de energia solar em aviário na Granja Dalva em Cacoal-RO.

Uma pesquisa iniciada pela Embrapa Agroenergia busca produzir diesel verde a partir de carcaças de 
aves, através da hidrogenação do bio-óleo de resíduos ósseos dessas aves. Os pesquisadores têm por objetivo realizar o aproveitamento da matéria-prima que usualmente é descartada sem nenhum tipo de produção de diesel renovável (SANTOS et al., 2016). O uso da energia solar (Figura 5) está em crescimento no ramo da avicultura uma vez que, o consumo de energia nos aviários é alta e os avicultores perceberam nesta tecnologia um investimento satisfatório (ROSA, 2005; VILVERT et al., 2020).

O tratamento de efluentes de abatedouro de frangos por sistema de reatores anaeróbios em dois estágios apresentou alto desempenho na remoção de sólidos e carga orgânica, podendo ser uma alternativa viável para o tratamento de águas residuárias de frigoríficos, porque oferece bons resultados de remoção e baixo custo de implantação (RODRIGUES et al., 2016).

\section{Marketing comercial na Avicultura na Amazônia Legal}

O marketing desempenha um papel importante nos ramos comerciais, pois a partir da divulgação de seus produtos ganham a confiança de seus consumidores, porém ainda há deficiência no marketing comercial e digital das marcas regionais na Amazônia Legal. Propagandas em rádios, televisão e redes sociais deveriam ser mais explorados. Um exemplo seria evidenciar que frigoríficos regionais além de proporcionarem mais empregos locais, também podem gerar uma carne de ótima qualidade, pois o tempo entre a produção e o consumo é menor. Isso fortalece a população a dar preferência às marcas regionais e consequentemente melhoram o poder econômico e a qualidade de vida da população local.

\section{CONCLUSÕES}

A Amazônia Legal ainda se apresenta pouco desenvolvida com relação à avicultura em relação ao restante do país. Principalmente, a parte da Amazônia Ocidental que apresenta o estado do Acre e Roraima com apenas um estabelecimento de beneficiamento de aves e ovos cadastrados com Serviço de Inspeção Estadual, e Amazonas apenas dois estabelecimentos. O estado de Rondônia é o que mais se destaca com 5 estabelecimentos cadastrados. No entanto, quanto à parte da Amazônia Oriental, o estado do Maranhão não apresenta nenhum estabelecimento de beneficiamento de aves e ovos cadastrados com Serviço de Inspeção Estadual, Pará apresenta três estabelecimentos e Tocantins apresenta um estabelecimento. Contudo, não foram encontrados registros para Amapá e Mato Grosso.

Em relação aos estabelecimentos com Serviço de Inspeção Federal na Amazônia Ocidental apenas o estado de Rondônia possui esse tipo de estabelecimentos contando com três unidades. Entretanto, na Amazônia Oriental o estado do Pará apresenta 3 unidades e o estado do Tocantins apresenta uma unidade. No entanto, Mato Grosso se destaca com 5 abatedouros frigoríficos de aves e é o único que exporta carne de aves. Destaca-se que os Serviços de Inspeção Municipais não foram analisados nesse estudo e que esses possuem grande relevância para a segurança alimentar local. E, apesar dos benefícios da avicultura para a Amazônia Legal estudos de rentabilidade são necessários para analisar se a atividade é viável aos produtores em cada estado pelo fato de os insumos como o milho e a soja poderem ser adquiridos de outras regiões, e principalmente em momentos de crise mundial. Também se faz necessária a maior aplicação das técnicas 
inovadoras sustentáveis e ampliação do marketing comercial na avicultura na Amazônia Legal para o desenvolvimento sustentável da região.

\section{REFERÊNCIAS}

ABNT. Associação Brasileira de Normas Técnicas. NBR 16389:2015. Avicultura: Produção, abate, processamento e identificação do frango caipira, colonial ou capoeira. ABNT, 2015.

ABPA. Associação Brasileira de Proteína Animal. Gráficos dos setores, Aves e Ovos. ABPA, 2021.

ADAF. Agência de Defesa Agropecuária e Florestal do Amazonas. Estabelecimentos avícolas aptos. ADAF, 2020.

ADAF. Agência de Defesa Agropecuária e Florestal do Amazonas. Lista de estabelecimentos com SIE. ADAF, 2021.

ADAPEC. Agência de Defesa Agropecuária do Tocantins. Granjas Registradas no Tocantins. ADAPEC, 2020.

ADEPARA. Agência de Defesa Agropecuária do Estado do Pará. Registro de granjas no estado do Pará. ADEPARA, 2020.

ADEPARA. Agência de Defesa Agropecuária do Estado do Pará. Estabelecimentos com registro gerência de carnes ovos, e derivados/serviço de inspeção estadual. ADEPARA, 2020b.

AGED. Agência Estadual de Defesa Agropecuária do Maranhão. Estabelecimentos avícolas comerciais registrados no maranhão. AGED, 2020.

AGED. Agência Estadual de Defesa Agropecuária do Maranhão. Estabelecimentos em atividade S.I.E./MA. AGED, 2020b.

ANATER. Agência Nacional de Assistência Técnica e Extensão Rural. Avicultura transforma a vida de famílias rurais em Rondônia. ANATER, 2021.

ARAÚJO, V. S.. Análise dos investimentos em avicultura do Programa Bolsa Floresta na Reserva de Desenvolvimento Sustentável do Uatumã. Dissertação (Mestrado em Gestão de Áreas Protegidas na Amazônia) - Instituto Nacional de Pesquisas da Amazônia, Manaus, 2013.

ARSHAD, M. S.; AMJAD, Z.; YASIN, M.; SAEED, F.; IMRAN, A.; SOHAIB, M.; ANJUM, F. M.; HUSSAIN, S.. Quality and stability evaluation of chicken meat treated with gamma irradiation and turmeric powder. International Journal of Food Properties, v.22, n.1, p.153-171, 2019. DOI: http://doi.org/10.1080/10942912.2019.1575395

BECK, A. B.. Aplicação da metodologia multicritério de apoio à decisão nas relações entre produtores rurais e agroindústria na cadeia da avicultura de corte. Dissertação (Mestrado em Agronegócios) - Universidade Federal do Rio Grande do Sul, Porto Alegre, 2015.

BELUSSO, D.; HESPANHOL, A. N.. A evolução da avicultura industrial brasileira e seus efeitos territoriais. Revista Percurso, v.2, n.1, p.25-51, 2010.
BOROVIEC, B. B.; GASPAROTTO, P. H. G.; DANTAS FILHO, J, V.; PEIXOTO, R. M.; VIANA, G. A.; ROCHA, A. S. C. M.; DAUDT, C.; SILVA, F. R. C.. Occurrence of Ascaridia galli and Heterakis gallinarum in Guinea Fowl (Numida meleagris) in the State of Rondônia, Brazil. Acta Scientiae Veterinariae, v.48, n.1, p.487-490, 2020. DOI: http://doi.org/10.22456/1679$\underline{9216.100099}$

CRUZ, F. G. G.; RUFFINO, J. P. F.; FEIJÓ, J. C.; DAMASCENO, J. L.; COSTA, A. P. G. C.. Perfil socioeconômico da avicultura no setor primário do estado do Amazonas, Brasil. Revista em Agronegócio e Meio Ambiente, v.9, n.2, p. 371-391, 2016. DOI: http://dx.doi.org/10.17765/2176-9168.2016v9n2p371$\underline{39}$

CUNHA, F. L.; CALIXTO, F. A. A.; CARNEIRO, C. S.; CARRIJO, K. F.. Processamento, pasteurização, desidratação e outros processos similares de conservação de ovos de consumo. Publicações em Medicina Veterinária, v.6, n.31, 2012.

EMATER. Entidade Autárquica de Assistência Técnica e Extensão Rural do Estado de Rondônia. Emater-RO e Conab garantem a agricultores familiares de Rondônia acesso a estoques governamentais em condições de igualdade. EMATER, 2021.

EMBRAPA. Empresa Brasileira de Pesquisa Agropecuária. Sistema Alternativo de Criação de Galinhas Caipiras. 2 ed. EMBRAPA, 2018.

EMBRAPA. Empresa Brasileira de Pesquisa Agropecuária. Estatísticas: Mundo Frangos de corte. EMBRAPA 2021.

FERREIRA, C. G. T.; BEZERRA, A. C. S.; AHID, S. M. M. Inquérito Ectoparasitológico em galinhas caipiras, Gallus gallus domesticus L., do município de Apodi, Rio Grande do Norte, Brasil. Revista Brasileira de Zoociências, v.12, n.3, p.249-256, 2010.

FERREIRA, L. D.. Estudo da logística de transporte da exportação de frango no Brasil com foco no caso do Distrito Federal. Monografia (Bacharelado em Engenharia Civil) Centro Universitário de Brasília, Brasília, 2018.

IDAF. Instituto de Defesa Agropecuária e Florestal do Estado do Acre. Ofício/IDAF/PESA no 002/2021: Informações avicultura no Estado do Acre. Rio Branco: IDAF, 2021.

IDARON. Agência de Defesa Sanitária Agrosilvopastoril do Estado de Rondônia. Estabelecimentos avícolas comerciais e de reprodução registrados/certificados/cadastrados/protocolados em Rondônia. IDARON, 2020a.

IDARON. Agência de Defesa Sanitária Agrosilvopastoril do Estado de Rondônia. Estabelecimentos registrados no SIE/RO. IDARON, 2020b.

IDARON. Agência de Defesa Sanitária Agrosilvopastoril do 
Estado de Rondônia. Estabelecimentos Avícolas Comerciais e de Reprodução Registrados. IDARON, 2021.

JUNQUEIRA, J. B.. Aplicação de biofertilizante, composto e uréia na produção de capim tanzânia (Panicum maximum, Jacq.) sob irrigação. Tese (Doutorado em Zootecnia) Universidade Estadual Paulista "Julio de Mesquita Filho", Jaboticabal, 2015.

LANSING, S.; BOTERO, R. B.; MARTIN, J. F.. Waste treatment and biogas quality in small-scale agricultural digesters. Bioresource Technology, v.99, p.5881-5890, 2008. DOI: http://doi.org/10.1016/j.biortech.2007.09.090

LIMA, P. G. B.. Strengthening Livelihood Flows on Payment for Environmental Services through Local Lenses: Evidences from the Bolsa Floresta Programme. Journal of Sustainable Development Studies, v.7, n.1, p.52-83, 2014.

MAPA. Ministério da Agricultura, Pecuária e Abastecimento. Quantidade de Abate Estadual por Ano/Espécie. MAPA, 2020a.

MAPA. Ministério da Agricultura, Pecuária e Abastecimento. Registro de Estabelecimentos: SIF ou ER. MAPA, 2020b.

MAPA. Ministério da Agricultura, Pecuária e Abastecimento. Relação de Produtos Autorizados para os Estabelecimentos Brasileiros Exportarem por País. MAPA, 2021.

OCDE. Organização para a Cooperação e Desenvolvimento Econômico. Perspectivas Agrícolas 2020-2029. OCDE, 2020.

PAULINO, M. T. F.; OLIVEIRA, E. M.; GRIESER, D. O.; TOLEDO, J. B.. Criação de frangos de corte e acondicionamento térmico em suas instalações: Revisão. Publicações em Medicina Veterinária, v.13, n.2, p.1-14, 2019. DOI: http://doi.org/10.31533/pubvet.v13n3a280.1-14

PEREIRA, A. S.; SHITSUKA, D. M.; PARREIRA, F. J.; SHITSUKA, R.. Metodologia da pesquisa científica. Santa Maria: UFSM, 2018.

PIMENTEL, C. N. M.; GODOT, T. M. C.; FIGUEIREDO, E. L.. Microbiological evaluation of chickenmeatsold in themunicipality of Castanhal, Pará. Brazilian Journal of Development, v.5, n.10, p.21848-21856, 2019. DOI: http://doi.org/10.34117/bjdv5n10-325

QUINZEIRO NETO, T. Q.; BESERRA JÚNIOR, J. S.; COSTA, J. B.; PINHO, A. K. S.; SANTOS, J. J. R. S.; BRASIL, E. P.; SANTOS JUNIOR, J. B.. Manual do sistema de produção sustentável de galinhas caipiras - (Procap): orientações básicas para construção do galinheiro, manejo sustentável e equipamentos. Brasília: Embrapa, 2017.

RODRIGUES, L. S.; LOPES, B. C.; LIMA, C. A.; RIBEIRO, M. C.; SANTOS, R. P.; SILVA, I. J.. Tratamento de efluentes de abatedouro de frangos por meio de reator UASB seguido de filtro anaeróbio. Arquivo Brasileiro de Medicina Veterinária e Zootecnia, v.68, n.1. p.97-103, 2016. DOI: http://doi.org/10.1590/1678-4162-7809

RODRIGUES, W. O. P.; GARCIA, R. G.; NAAS, I. A.; ROSA, C. O.; CALDARELLI, C. E.. Evolução da avicultura de corte no Brasil. Enciclopédia Biosfera, v.10, n.18, p.1666-1684, 2014.

ROSA, A.. Fundamentals of renewable energy processes. Sacramento: Elsevier, 2005.

SANTOS, I. F. S.; BARROS, R. M.; TIAGO FILHO, G. L. Electricity generation from biogas of anaerobic wastewater treatment plants in Brazil: an assessment of feasibility and potential. Journal of Cleaner Production, v.126, p.504-514, 2016. DOI: http://doi.org/10.1016/j.jclepro.2016.03.072

SANTOS, J. L. V.; LACERDA JÚNIOR, J. A. C.; SANTOS, É. C. P.; SANTOS, G. B.; SÁ, H. M.; QUEIROZ, E. O; PAZDIORA, R. D.; MOREIRA FILHO, A. L. B.. Avaliação dos parâmetros ambientais e fisiológicos para frangos de corte linhagem caipira em diferentes fases de criação na Amazônia Ocidental. Brazilian Journal of Development, v.6, n.8, p.61607-61622, 2020. DOI: http://doi.org/10.34117/bjdv6n8-546

SILVA, R. M. A.; AQUINO, J. R.; COSTA, F. B.; NUNES, E. M.. Productive and socio-environmental characteristics of family farming in the Brazilian semiarid region: evidences from the 2017 Agricultural Census. Desenvolvimento e Meio Ambiente, v.55, p.314-338, 2020. DOI: http://doi.org/10.5380/dma.v55i0.73745

SOUZA, S. B.. Processo de transição sociotécnica em um entreposto avícola em Cacoal/RO. Dissertação (Mestrado em Administração) - Universidade Federal de Rondônia, Porto Velho, 2019.

VILVERT, A. J.; SALDEIRA JUNIOR, J. C.; BAUTITZ, I. R.; ZENATTI, D. C.; ANDRADE, M. G.; HERMES, E.. Minimization of energy demand in slaughterhouses: Estimated production of biogas generated from the effluent. Renewable and Sustainable Energy Reviews, e109613, 2019. DOI: http://doi.org/10.1016/j.rser.2019.109613

A CBPC - Companhia Brasileira de Produção Científica (CNPJ: 11.221.422/0001-03) detém os direitos materiais desta publicação. Os direitos referem-se à publicação do trabalho em qualquer parte do mundo, incluindo os direitos às renovač̃os, expansões e disseminaç̃es da contribuiç̃o, bem como outros direitos subsidiários. Todos os trabalhos publicados eletronicamente poderão posteriormente ser publicados em coletâneas impressas sob coordenação da Sustenere Publishing, da Companhia Brasileira de Produção Científica e seus parceiros autorizados. Os (as) autores (as) preservam os direitos autorais, mas não têm permissão para a publicação da contribuição em outro meio, impresso ou digital, em português ou em tradução. 